\title{
Investigation the Optimization of Machining Parameters to Surface Roughness in Free Form Surface of Composite Material
}

\author{
Reem S. Kazaal* Wisam K. Hamdan** \\ *Department of Production Engineering and Metallurgy/ University of Technology \\ **Department of Biomedical Engineering / University of Technology \\ *Email: sabahreem18@yahoo.com \\ **Email: wisamuot@yahoo.com
}

(Received 16 July 2018; accepted 31 October 2018)

https://doi.org/10.22153/kej.2019.10.001

\begin{abstract}
The aim of this research is to investigation the optimization of the machining parameters (spindle speed, feed rate, depth of cut, diameter of cutter and number of flutes of cutter) of surface roughness for free-form surface of composite material (Aluminum 6061 reinforced boron carbide) by using HSS uncoated flat end mill cutters which are rare use of the free-form surface. Side milling (profile) is the method used in this study by CNC vertical milling machine. The purpose of using ANFIS to obtain the better prediction of surface roughness values and decreased of the error prediction value and get optimum machining parameters by using Taguchi method for the best surface roughness at spindle speed 4500 r.p.m, $920 \mathrm{~mm} / \mathrm{rev}$ feed rate, $0.6 \mathrm{~mm}$ depth of cut, $10 \mathrm{~mm}$ diameter, 2 flute.
\end{abstract}

Keywords: Optimization, surface roughness, free-form surface, composite material, Taguchi method, milling machine.

\section{Introduction}

Work has been done on composite material to achieve the best surface roughness relative to free form surfaces using end mill cutter on the side of the form by using vertical CNC milling machine. Mustafa Kurt et al. [1] for the purpose of pleasing customers, many free surface products are designed to enhance their aesthetic appearance; these products can have complicated surfaces to meet functional requirements, which necessitate specific aerodynamic, optical, medical, structural and processing characteristics. This study addressed the effects of factors on surface roughness and dimensional machining errors during free-form surface machining using experimental works using a ball-end mill in a 3axis CNC milling machine. J.-M. Redonnet et al. [2] End-milling of free-form surfaces on 5-axis NC machine tools is a complex problem when non-convex surfaces interference in end milling which causes a risk between the tool and the surface the research based on the algorithms which turn works to locate the tool and thus improve the position of the tool relative to the goals set for each probability. Lufeng CHEN et al. [3] the goal behind this study that the specific type of iso-planar milling for both roughing and finishing, has developed a process algorithm an optimal surface for freeform surface. While the algorithm is proposed solution for iso-planar milling, it can be easily appropriate to other types of milling strategy such as contour milling. Both computer simulation and physical cutting experiments of the suggested method have convincingly demonstrated its makings over the traditional simple offset method. Rybicki [4] a milling method with variable parameters such as speed, feed rate and diameter of cutter for surface roughness more homogeneous with greater productivity relative to free form surface. Based on the roughness measurement results for the 
experiments, many problems have been set: necessity of the surface curvature pre-filtering from primary profile, necessity of $2 \mathrm{D}$ roughness assessment in two perpendicular directions. Shaghayegh Shajari et al. [5] discussed the effect of employing different cutter path strategies on cutting force, surface texture, and machining time when ball end milling of low curvature convex surface; have shown that the use of different cutter path strategies when finishing ball end milling of low curvature convex surfaces has more effects on the cutting forces, surface texture, and machining time. In general, radial cutter path appears will give its preferred results with respect to the homogenous surface composition and obtain less cutting forces. Rodrigo Henriques Lopes da Silva et al. [6] using a method tool path strategies on side milling with a vertical end mill. The main objective of this study is to evaluate the path's effect on the cutting forces and roughness of the surface, and simultaneously the effect of milling parameters (cutting speed, feed, and path period). Then apply experiments randomly and a Taguchi Method was applied and concludes that the trajectories of the tool significantly effect on surface roughness. Istvan SZALOKI et al. [7] studied surface roughness (Ra, Rz, Rt, Rp, RSm) and effect feed on the material (aluminum metal matrix composite) at constant speed with three value of feed per tooth. the search results proved that the $\mathrm{Rz}$ and $\mathrm{Rp}$ parameters are more able to give the influence of the milling parameters on the quality of the surface. The aim from these studies to obtain the best parameters to less roughness for convex region in free form surface.

\section{Experimental Equipments}

\subsection{Materials}

Composite material (aluminumT-6061 reinforcement with $4 \%$ boron carbide) used in this work and prepared by stir casting method. The metal matrix composite express one of the significant composite because have various applications like automotive and aerospace industries due to superior properties compared with conventional alloy [8]. This material has been inspected in general company for engineering inspection and rehabilitation (S.I.E.R)/ (Lab. \& E.I.Dep.) for chemical composition shown in table (1).
Table 1,

Shown the chemical composition of $(\mathrm{Al}+\mathrm{B} 4 \mathrm{C})$ composite material.

\begin{tabular}{llll}
\hline elements & \multicolumn{1}{c}{$\%$} & elements & \multicolumn{1}{c}{$\%$} \\
\hline $\mathrm{Si}$ & 0.756 & $\mathrm{Cr}$ & 0.206 \\
$\mathrm{Fe}$ & 0.422 & $\mathrm{Ni}$ & 0.006 \\
$\mathrm{Cu}$ & 0.309 & $\mathrm{Zn}$ & 0.013 \\
$\mathrm{Mn}$ & 0.060 & $\mathrm{~Pb}$ & 0.010 \\
$\mathrm{Mg}$ & 0.88 & $\mathrm{Ti}$ & 0.023 \\
$\mathrm{~V}$ & 0.008 & $\mathrm{~B} 4 \mathrm{C}$ & $4 \%$ \\
$\mathrm{Al}$ & Bal. & & \\
\hline
\end{tabular}

\subsection{Machining}

CNC vertical milling C-tek (KM-80 D) pc BASED machine has been used to machining the composite material $(\mathrm{Al}+\mathrm{B} 4 \mathrm{C})$ by using uncoated HSS end-mill cutter with different diameters $(6,8$, and 10$) \mathrm{mm}$; and number of flutes $(2,3$, and 4$)$.the machining (side milling) has been performed on free form surface shown in Fig (1) dependent on various parameters spindle speed, feed rate, depth of cut, diameter of cutter and number of flutes of cutter under dry cutting condition to obtain the better roughness of the free form surface because of the rare use of this type of tool to machine this surface .

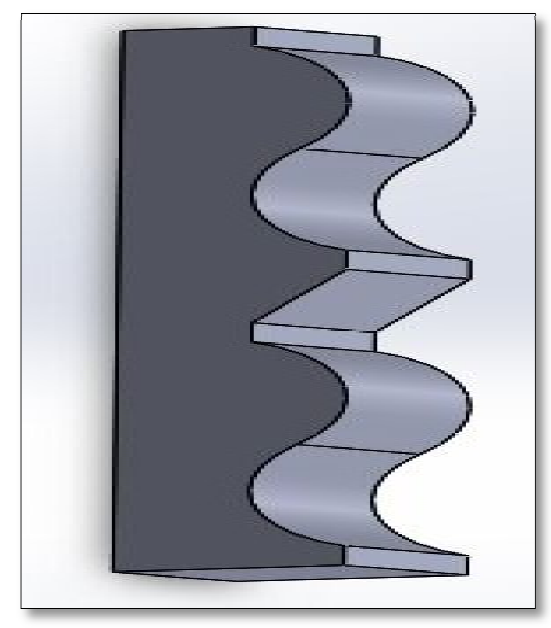

Fig. 1. Shown the design of free form surface.

The dimensions of the form as shown in figure (2). 


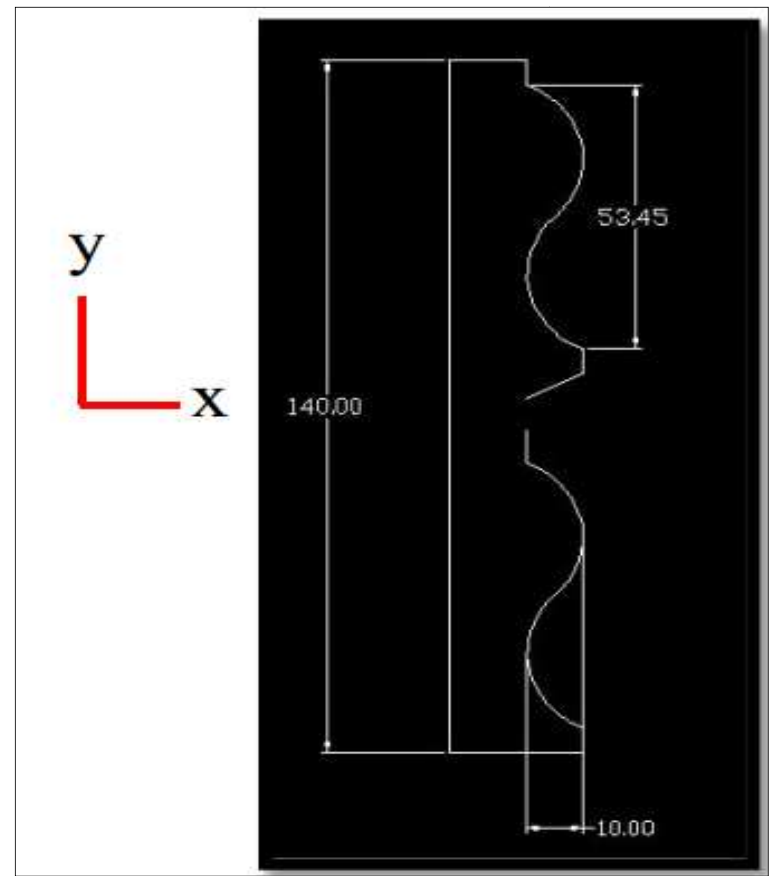

Fig. 2. Shown the dimension of the form.

\section{Taguchi methods for designing experiments}

Taguchi has developed a system for the application testing designed; this system has taken the design of experiments from the exclusive world of the statistician and making them more visible in the world of manufacturing. The contributions of the system also made the user simpler in obtaining fewer tests in experimental designs [9].

Taguchi submitted, the use of the loss function to measure the performance feature deviating from the required value, further convert into a signal-to-noise ratio. There are three types of the performance characteristic in the analysis of the signal-to-noise ratio (the lower-thebetter, the higher-the-better, and the nominal- thebetter) [10].in this study lower the better was used to suggest of surface roughness in equation (1)

$S / N_{i j}=-10 \log \left(\frac{1}{n} \sum_{j=1}^{n} y_{i j}^{2}\right)$

Where:

$S / N_{i j}$ : signal to noise ratio

$y_{i j}=$ observed value of the $i_{t h}$ experiment at the $j_{\text {th }}$ test.

$\mathrm{n}=$ number of observation in a trials.

\section{Surface Roughness Measurement}

Surface roughness was measured by using roughness measured device (MarSurfPS1) shown in Fig (3) for 18 experiments designed according to the Taguchi method orthogonal array with mixed levels $L_{18}\left(4^{3} \times 1^{6}\right)$; table (2) shows the used control parameters and their levels.

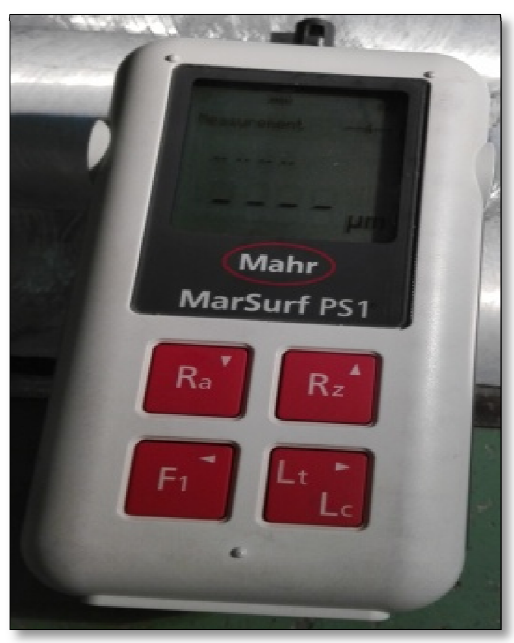

Fig. 3. Roughness device (Marsurfps1).

Table 2,

The control parameters and their levels

\begin{tabular}{llllll}
\hline No. & notation & $\begin{array}{l}\text { No.of } \\
\text { level }\end{array}$ & $\begin{array}{l}\text { Low } \\
\text { value }\end{array}$ & $\begin{array}{l}\text { High } \\
\text { value }\end{array}$ & unit \\
\hline 1 & A & 6 & 2500 & 5000 & r.p.m \\
2 & B & 3 & 120 & 920 & $\mathrm{~mm} / \mathrm{rev}$ \\
3 & C & 3 & 0.2 & 0.6 & $\mathrm{~mm}$ \\
4 & D & 3 & 6 & 10 & $\mathrm{~mm}$ \\
5 & E & 3 & 2 & 4 & \\
\hline
\end{tabular}

When:

A: spindle Speed, B: feed rate, c: depth of cut D: diameter of cutter, E: number of flutes.

The roughness has been measured for two areas (convex and concave) of free form surface shown in Fig (4). 


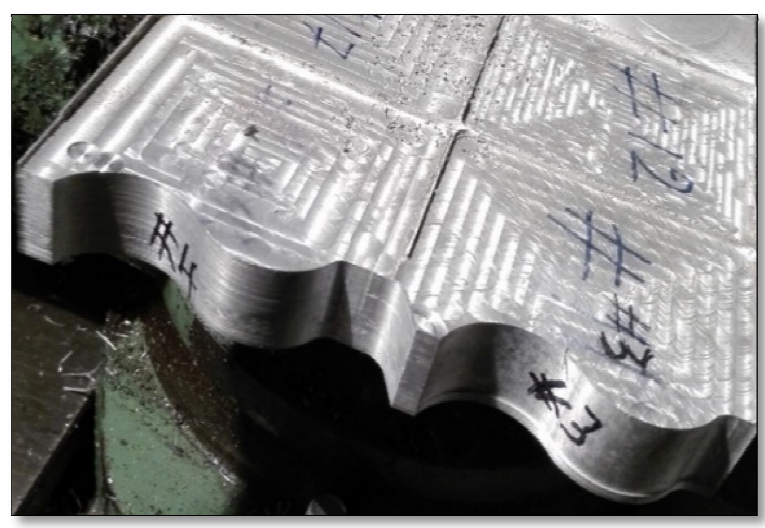

Fig. 4. The model of the work.

The results obtained for the values of the roughness shown in table (3) found in convex area less than concave area as the diagram (1) described below.

Table 3,

The roughness value in convex and concave areas

\begin{tabular}{llllcccl}
\hline No. & A & B & C & D & E & Ra.1 & Ra.2 \\
\hline 1 & 2500 & 120 & 0.2 & 6 & 2 & 1.123 & 1.423 \\
2 & 2500 & 520 & 0.4 & 8 & 3 & 4.510 & 5.140 \\
3 & 2500 & 920 & 0.6 & 10 & 4 & 1.660 & 1.128 \\
4 & 3000 & 120 & 0.2 & 8 & 3 & 4.091 & 5.130 \\
5 & 3000 & 520 & 0.4 & 10 & 4 & 0.966 & 1.081 \\
6 & 3000 & 920 & 0.6 & 6 & 2 & 2.052 & 1.650 \\
7 & 3500 & 120 & 0.4 & 6 & 4 & 2.745 & 3.166 \\
8 & 3500 & 520 & 0.6 & 8 & 2 & 1.038 & 1.067 \\
9 & 3500 & 920 & 0.2 & 10 & 3 & 2.214 & 2.27 \\
10 & 4000 & 120 & 0.6 & 10 & 3 & 2.581 & 3.592 \\
11 & 4000 & 520 & 0.2 & 6 & 4 & 4.576 & 3.462 \\
12 & 4000 & 920 & 0.4 & 8 & 2 & 1.436 & 1.312 \\
13 & 4500 & 120 & 0.4 & 10 & 2 & 1.063 & 1.073 \\
14 & 4500 & 520 & 0.6 & 6 & 3 & 1.506 & 1.568 \\
15 & 4500 & 920 & 0.2 & 8 & 4 & 1.076 & 1.424 \\
16 & 5000 & 120 & 0.6 & 8 & 4 & 1.381 & 1.590 \\
17 & 5000 & 520 & 0.2 & 10 & 2 & 0.806 & 1.145 \\
18 & 5000 & 920 & 0.4 & 6 & 3 & 1.747 & 4.159 \\
\hline
\end{tabular}

Ra.1: the roughness in convex surface.

Ra.2: the roughness in concave surface.

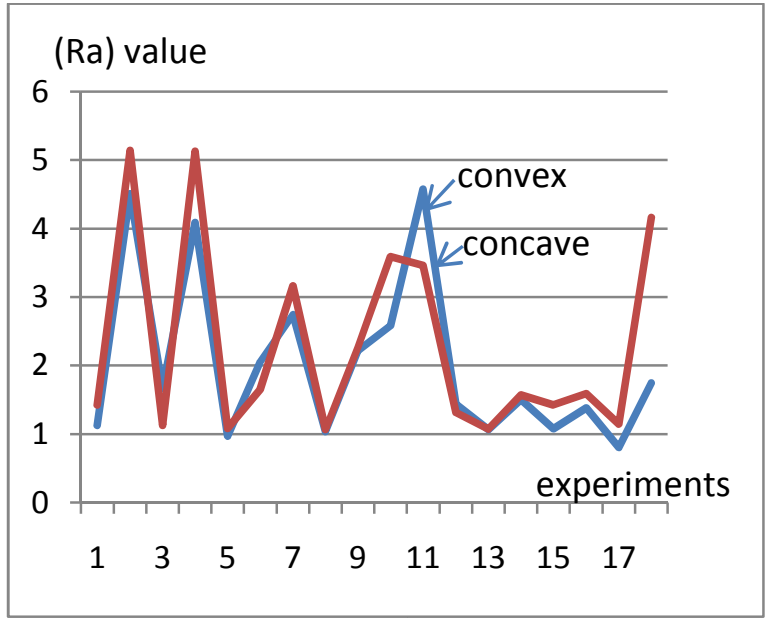

Fig. 5. Shown the convex and concave roughness.

\section{Prediction by (ANFIS)}

adaptive network based fuzzy inference system means a fuzzy inference system perform in the framework of adaptive networks. Soft computing oncoming including artificial neural networks and fuzzy inference have been used vastly to model expert attitude. Using given input and output data, the suggest ANFIS can put up mapping depended on both human knowledge (in the form of fuzzy if-then rules) and hybrid learning algorithm. In modeling and simulation, the ANFIS strategy is utilize to model nonlinear functions, to control the most important factor of machine and predict it. More effective, faster response [11].

The program consists of eight types of membership functions; each type contains two components constant and linear function thus becoming 16 fuzzy rules. In this study ANFIS tool in matlab software program was used to predict the surface roughness to obtain more accurate values after it was found that the error value was very few among the practical and predictive experiments; through the experiments conducted through the training and testing date found the triangular membership function type and input of membership function $=2$; type linear and epochs 200 shown in Figure (6) found that is less error shown in table (4)

The equation of error:

Error $=\frac{\mid \text { Actual value }- \text { predicted value } \mid}{\text { Actual value }} \times 100 \%$ 


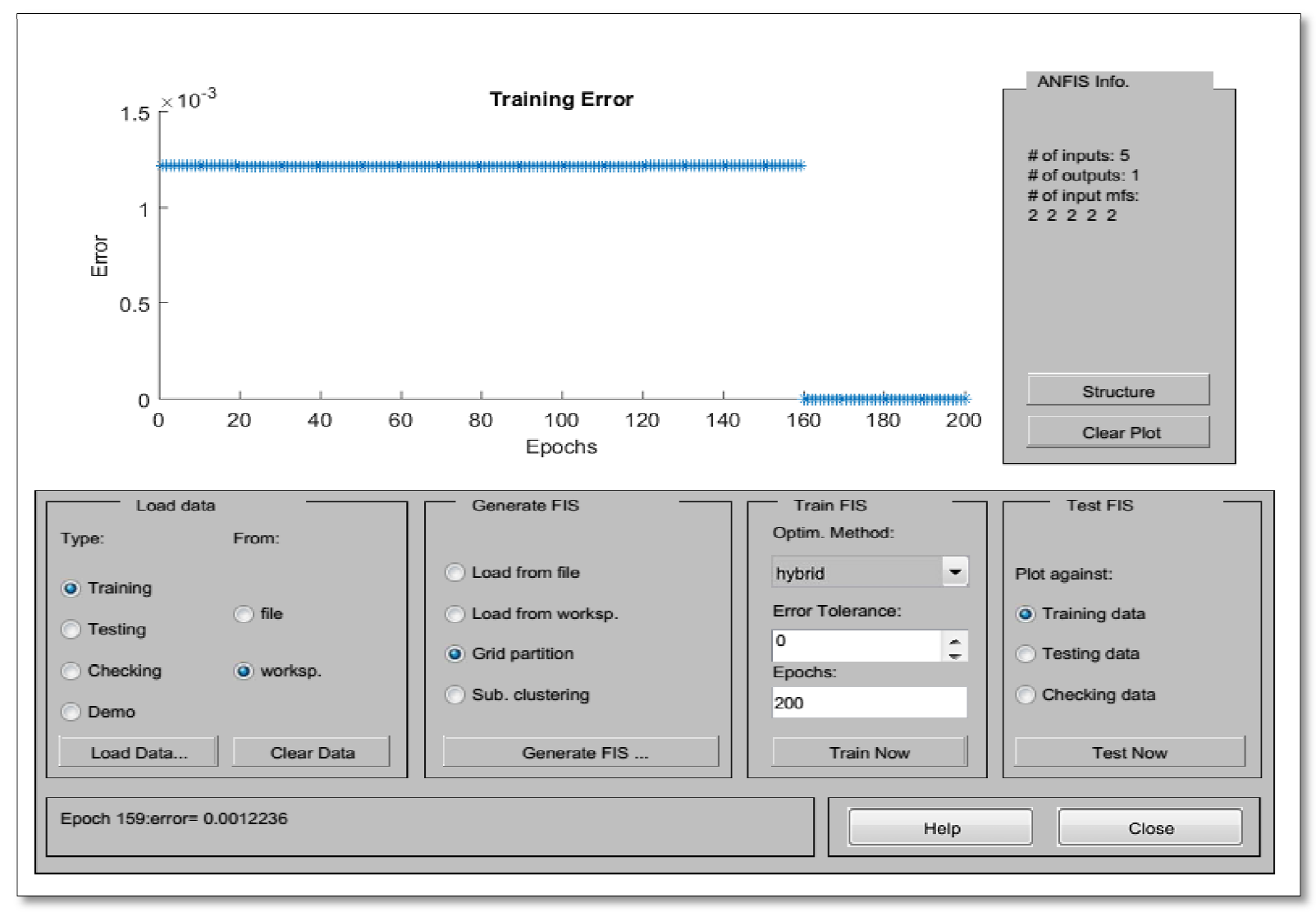

Fig. 6. Shown the membership function and epochs used for predict.

Table 4,

Shown the error percentage.

\begin{tabular}{llllllll}
\hline $\begin{array}{l}\text { No. of } \\
\text { experiments }\end{array}$ & $\begin{array}{l}\text { Actual } \\
\text { value }\end{array}$ & $\begin{array}{l}\text { Predict } \\
\text { value }\end{array}$ & Error \% & $\begin{array}{l}\text { No. of } \\
\text { experiments }\end{array}$ & $\begin{array}{l}\text { Actual } \\
\text { value }\end{array}$ & $\begin{array}{l}\text { Predict } \\
\text { value }\end{array}$ & Error \% \\
\hline 1 & 1.123 & 1.12 & 0.267 & 10 & 2.581 & 2.58 & 0.0387 \\
2 & 4.510 & 4.51 & 0 & 11 & 4.576 & 4.58 & 0.0874 \\
3 & 1.660 & 1.66 & 0 & 12 & 1.436 & 1.44 & 0.278 \\
4 & 4.091 & 4.09 & 0.0244 & 13 & 1.063 & 1.06 & 0.282 \\
5 & 0.966 & 0.967 & 0.103 & 14 & 1.506 & 1.50 & 0.398 \\
6 & 2.052 & 2.05 & 0.0974 & 15 & 1.076 & 1.08 & 0.3717 \\
7 & 2.745 & 2.75 & 0.6711 & 16 & 1.381 & 1.38 & 0.0724 \\
8 & 1.038 & 1.04 & 0.192 & 17 & 0.806 & 0.808 & 0.2481 \\
9 & 2.214 & 2.21 & 0.1806 & 18 & 1.747 & 1.75 & 0.1717 \\
\hline
\end{tabular}

\section{Analysis of Variance (ANOVA)}

The ANOVA performed to check the statistical significance of the process factors affecting the surface roughness through by separating the total variability of the $\mathrm{S} / \mathrm{N}$ ratios, can be calculated by the total squared deviations from the total mean of the $\mathrm{S} / \mathrm{N}$ ratio, into contributions by each of the process parameters and the error. F-test was carried out to judge the significant parameter affecting the roughness. The larger F-value was the ones that determine the most influential factor on performance. [12].

Analyzing the results using main effect plot and $\mathrm{SN}$ ratio to know the affect each parameter from low to high level Fig (7.a) and (7.b) shows main effect plot of surface roughness and for SN ratios in five Graphs and affect the chosen five machining parameters on surface roughness of free form surface. 


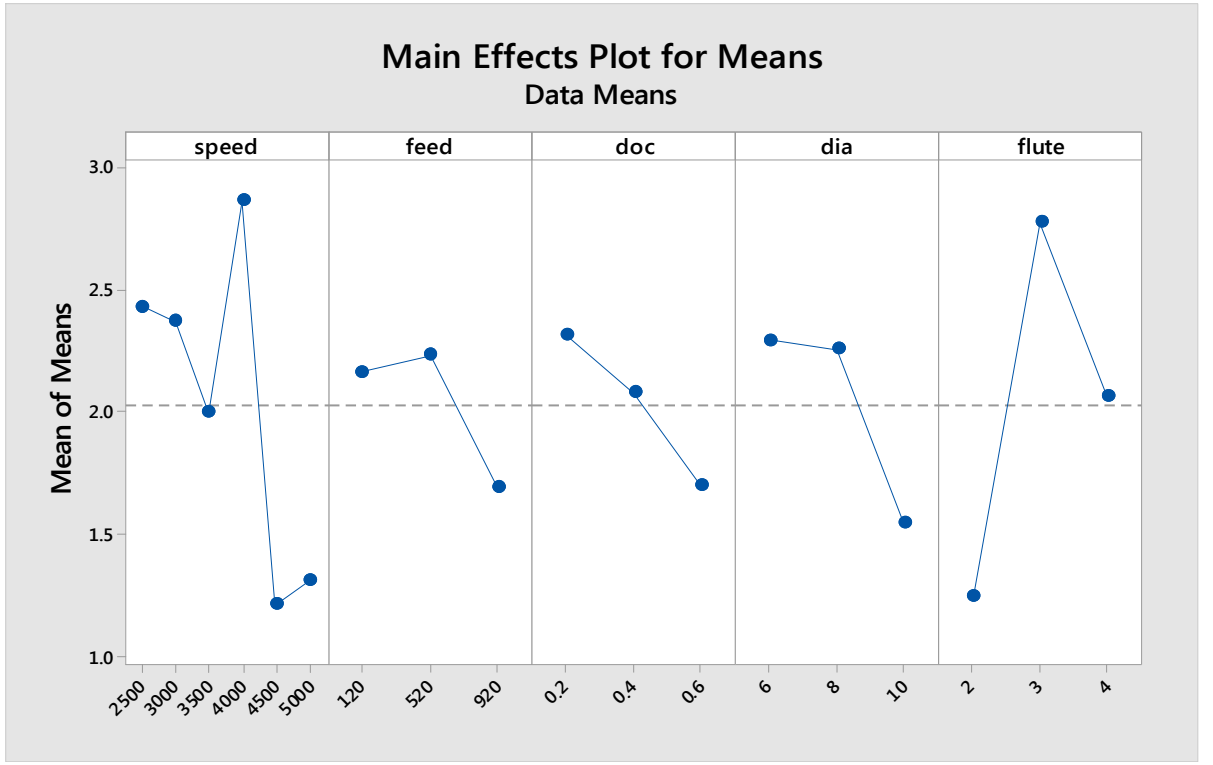

Fig. 7.a. Main effect plot for mean.

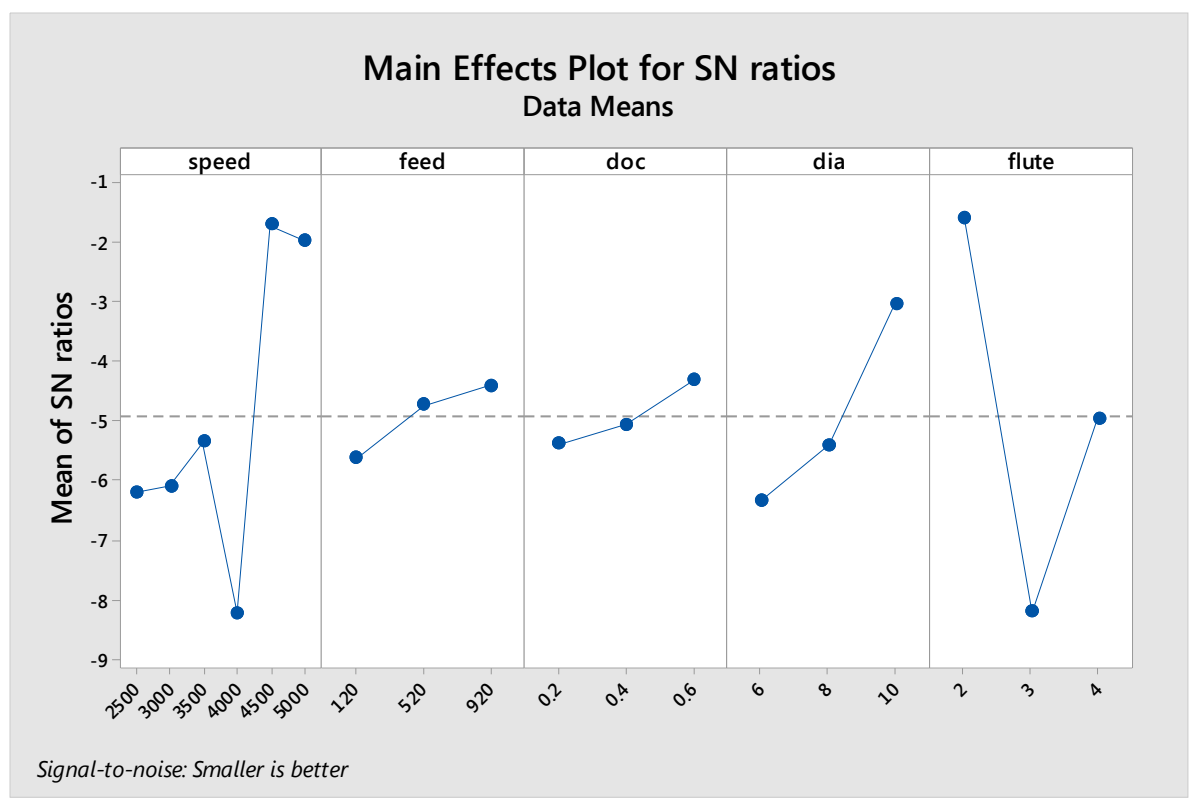

Fig. 7.b. Main effect plot for SN ratio.

The effect of combination parameters and how to influence on the surface roughness can be shown by the interaction plot shown in Fig (8). The minitab17 software program was used to create the ANOVA which illustrates the most effective factors to reduce roughness as shown in table (5). 


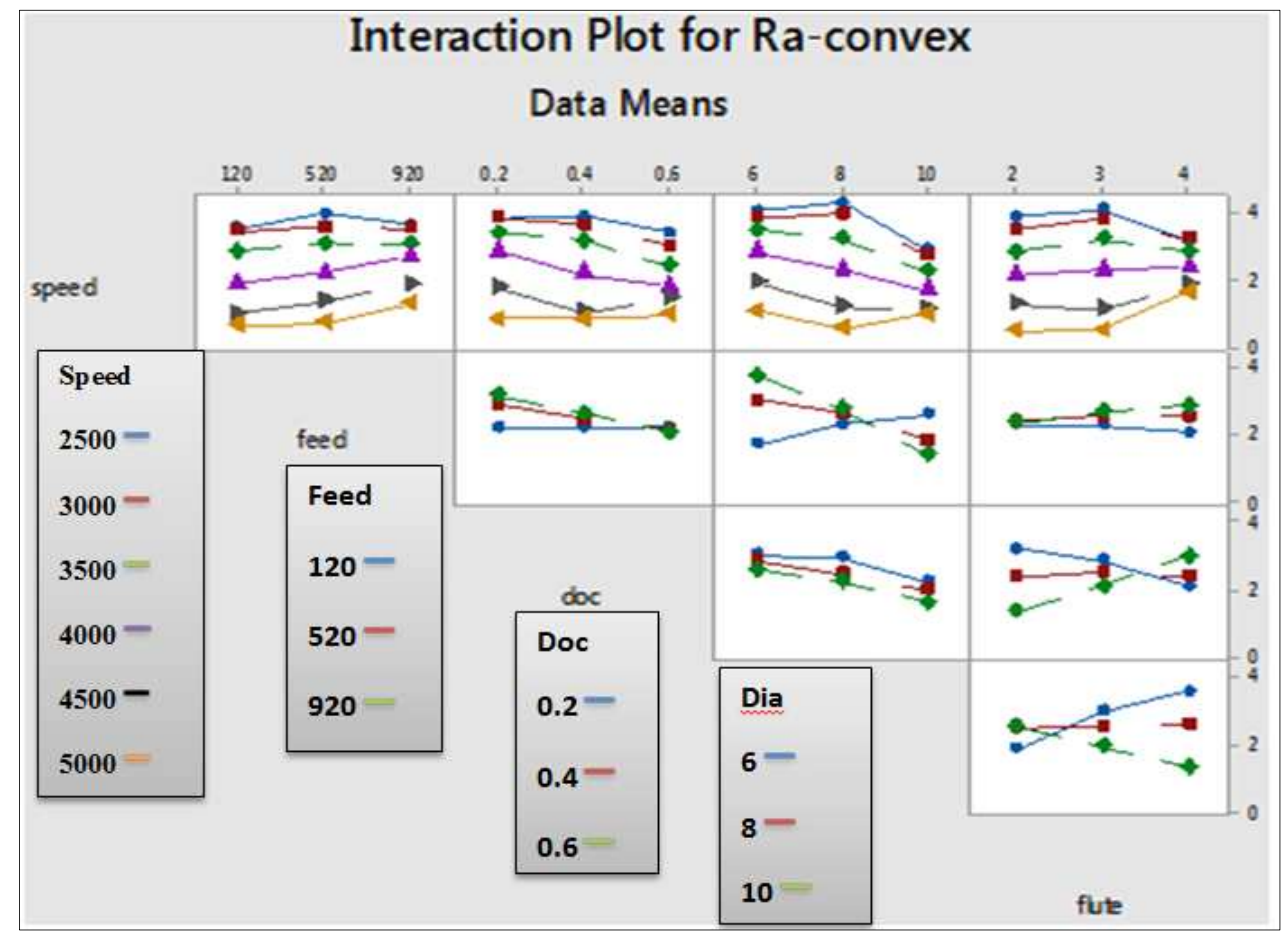

Fig. 8. Interaction plot of parameters.

Table 5,

Analysis of variance results of convex region in free form surface

\begin{tabular}{|c|c|c|c|c|c|c|}
\hline Source & DF & Adj SS & Adj MS & F-Value & P-Value & Contribution \\
\hline Model & 20 & 1084.06 & 54.203 & 59.21 & 0.000 & \\
\hline Linear & 5 & 638.98 & 127.796 & 139.60 & 0.000 & \\
\hline A & 1 & 527.78 & 527.779 & 576.55 & 0.000 & $82.597 \%$ \\
\hline B & 1 & 16.29 & 16.287 & 17.79 & 0.000 & $2.549 \%$ \\
\hline $\mathrm{C}$ & 1 & 29.15 & 29.153 & 31.85 & 0.000 & $4.561 \%$ \\
\hline $\mathrm{D}$ & 1 & 68.66 & 68.662 & 75.01 & 0.000 & $10.745 \%$ \\
\hline $\mathrm{E}$ & 1 & 2.53 & 2.529 & 2.76 & 0.097 & $0.395 \%$ \\
\hline Square & 5 & 10.71 & 2.141 & 2.34 & 0.041 & \\
\hline$A^{*} A$ & 1 & 6.69 & 6.686 & 7.30 & 0.007 & $62.464 \%$ \\
\hline $\mathrm{B} * \mathrm{~B}$ & 1 & 0.41 & 0.415 & 0.45 & 0.501 & $3.828 \%$ \\
\hline $\mathrm{C}^{*} \mathrm{C}$ & 1 & 0.03 & 0.026 & 0.03 & 0.866 & $0.2801 \%$ \\
\hline $\mathrm{D} * \mathrm{D}$ & 1 & 2.90 & 2.899 & 3.17 & 0.076 & $27.077 \%$ \\
\hline $\mathrm{E} * \mathrm{E}$ & 1 & 0.67 & 0.675 & 0.74 & 0.391 & $6.255 \%$ \\
\hline 2-Way Interaction & 10 & 438.73 & 43.873 & 47.93 & 0.000 & \\
\hline$A * B$ & 1 & 4.96 & 4.964 & 5.42 & 0.020 & $1.1305 \%$ \\
\hline $\mathrm{A}^{*} \mathrm{C}$ & 1 & 3.24 & 3.239 & 3.54 & 0.061 & $0.7384 \%$ \\
\hline$A * D$ & 1 & 7.90 & 7.902 & 8.63 & 0.003 & $1.8006 \%$ \\
\hline$A^{*} \mathrm{E}$ & 1 & 27.85 & 27.847 & 30.42 & 0.000 & $6.347 \%$ \\
\hline$B * C$ & 1 & 15.12 & 15.123 & 16.52 & 0.000 & $3.4463 \%$ \\
\hline$B * D$ & 1 & 152.38 & 152.378 & 166.46 & 0.000 & $34.731 \%$ \\
\hline$B * E$ & 1 & 8.00 & 7.998 & 8.74 & 0.003 & $1.823 \%$ \\
\hline$C * D$ & 1 & 0.43 & 0.429 & 0.47 & 0.494 & $0.0980 \%$ \\
\hline $\mathrm{C}^{*} \mathrm{E}$ & 1 & 100.56 & 100.565 & 109.86 & 0.000 & $22.920 \%$ \\
\hline $\mathrm{D} * \mathrm{E}$ & 1 & 115.40 & 115.400 & 126.06 & 0.000 & $26.303 \%$ \\
\hline Error & 465 & 425.67 & 0.915 & & & \\
\hline Lack-of-Fit & 455 & 425.67 & 0.936 & $*$ & $*$ & \\
\hline Pure Error & 10 & 0.000 & 0.000 & & & \\
\hline Total & 485 & 1509.73 & & & & $100 \%$ \\
\hline
\end{tabular}




\section{Optimization by using Taguchi Method}

Taguchi methods of experimental design provide a simple, effective and systematic approach for the optimization of experimental design for performance quality and for expected economic production. This method is a unique and powerful statistical experimental design technique, which greatly improves the engineering productivity [10]. Through the roughness value in Table (3) shown Above that the roughness values in the convex region less than the concave region; therefore, the optimization has been performed in the convex region.

Table 6,

The parameters and their levels

\begin{tabular}{cccccc}
\hline levels & \multicolumn{2}{l}{ parameters } & & & \\
\cline { 2 - 6 } & $\mathbf{A}$ & $\mathbf{B}$ & $\mathbf{C}$ & $\mathbf{D}$ & $\mathbf{E}$ \\
\hline 1 & 1 & 1 & 1 & 1 \\
2 & & & & \\
& 2 & 2 & 2 & 2 \\
4 & & & & \\
5 & 3 & 3 & 3 & 3 \\
6 & & & & \\
\hline
\end{tabular}

Through the Table (7) can be obtained the mean of Ra.convex for SN.

Table 7, mean of Ra for SN ratio

\begin{tabular}{llllll}
\hline level & \multicolumn{5}{c}{ parameters } \\
\cline { 2 - 6 } & $\mathbf{A}$ & $\mathbf{B}$ & $\mathbf{C}$ & $\mathbf{D}$ & $\mathbf{E}$ \\
\hline-6.198 & -5.643 & -5.988 & -6.335 & -2.209 \\
-6.272 & & & & \\
-5.365 & -5.413 & -5.157 & -5.412 & -8.208 \\
-8.234 & & & & \\
-1.721 & -4.416 & -4.327 & -3.725 & -5.055 \\
-3.153 & & & & \\
\hline
\end{tabular}

The large number was selected for all parameters in the table and take roughness values for the one level and divided on number of levels and applied in the equation (3)

$\mathrm{Ra}=\mathrm{A} 5+\mathrm{B} 3+\mathrm{C} 3+\mathrm{D} 3+\mathrm{E} 1-(\mathrm{N}-1) \mathrm{T}$

Where:

$\mathrm{N}=$ number of parameters.

$\mathrm{T}=$ the mean of the trails.

$\mathrm{Ra}=0.7101 \mu \mathrm{m}$.

\section{The Result and Discussion}

The analysis of variance can be used to identify the effect of factors in reducing surface roughness and obtaining a highquality surface after showing the model summery in the Table (8) below; the convergence between practical R-Sq and predictive R-Sq (adj) experiments was very large and thus can be depended on the results of the analysis of variance (ANOVA) table.

Table 8,

Model summary.

\begin{tabular}{llll}
\hline S & R-sq & R-sq (adj) & R-sq (pred) \\
\hline 0.956772 & $71.81 \%$ & $70.59 \%$ & $68.61 \%$ \\
\hline
\end{tabular}

Through the analysis of variance (ANOVA) table found the factor that affects a large amount to reduce the surface roughness in convex area of free form surface is spindle speed at 4500 r.p.m .This also has been found through main effect plot where the effect of influence $82.597 \%$.Through the interaction when combination between two parameters found the fisher test value (F-value) at $(B * D)=166.46$ that represent a large value this means that feed rate and diameter of cutter are considered important parameters to less the surface roughness in convex area to free form surface where was the feed rate $920 \mathrm{~mm} / \mathrm{rev}$ and $(10 \mathrm{~mm})$ diameter cutter were the best related roughness and its ratio $34.731 \%$ and it is fluent in diameter with flutes ;(2) flute express the better compared with other flutes .

\section{Conclusion}

In this study shown:

1. The more influential parameters to obtain the surface roughness in free form surface at convex area in composite material are spindle speed (4500 r.p.m) and number of two flutes when the cutting area is constant and heat a few because it is a beginning to cut and not to be built up edge on the edge of cutter and we can conclude that the diameter of cutter when increase the surface roughness decreased.

2. From the optimization by Taguchi method found that the best machining parameters at spindle speed (4500 r.p.m), feed rate (920 $\mathrm{mm} / \mathrm{rev})$, depth of cut $(0.6 \mathrm{~mm})$, diameter of cutter $(10 \mathrm{~mm})$ and number of flute (2) to obtain the best surface roughness. 


\section{Reference}

[1] Mustafa Kurt, Selim Hartomacýoð, Bilçen Mutlu,Uður Köklü” Minimization of the surface roughness and for merror on the milling of free-form surfaces using a grey ralational analysis" Original scientific article,pp.205-213, 2012.

[2] J.M. Redonnet, W. Rubio, F. Monies and G. Dessein" Optimising Tool Positioning for End-Mill Machining of Free-Form Surfaces on 5-Axis Machines for both Semi-Finishing and Finishing" International Journal Advancing Manufacturing Technol,2000.

[3] Lufeng CHEN, Pengcheng HU, Ming luo, Kai TANG "Optimal interface surface determination for 4 multi- axis freeform surface machining with 5 both roughing and finishing", Chinese Journal of Aeronautics, pp.15,2017.

[4] M Rybicki" Problems during Milling and Roughness Registration of Free-form Surfaces", Journal of Physics, 2014.

[5] Shaghayegh Shajari, Mohammad Hossein Sadeghi, and Hamed Hassanpour," The Influence of Tool Path Strategies on Cutting Force and Surface Texture during Ball End Milling of Low Curvature Convex Surfaces", the Scientific World Journal, pp.14,2014.

[6] Rodrigo Henriques Lopes da Silva \& Amauri Hassui 1" Cutting force and surface roughness depend on the tool path used in side milling: an experimental investigation", The International Journal of Advanced Manufacturing Technology, 2018.
[7] István SZALÓKI, Sándor SIPOS, Zsolt János VIHAROS "Aluminum-based MMC machining with carbide cutting tool" ICPM 2015 Congress 8th International Congress on Precision Machining, pp.151-156,2015.

[8] S Jeyakumar, K Marimuthu \&T Ramachandran "optimization of machining parameters of Al6061 composite to minimize the surface roughness-modelling using RSM and ANN' Indian Journal of Engineering \& Materials Sciences, Vol.22, pp.29-37,2014.

[9] M. Nalbant, H.Go"kkaya, G. Sur" Application of Taguchi method in the optimization of cutting parameters for surface roughness in turning", Materials and Design journal, 2007.

[10] S.S.Chaudhari, S.S. Khedkar , N.B. Borkar," Optimization of process parameters using Taguchi approach with minimum quantity lubrication for turning”, International Journal of Engineering Research and Applications (IJERA), Vol. 1, Issue 4, pp.1268-1273.

[11] Navneet Walia, Harsukhpreet Singh, Anurag Sharma" ANFIS: Adaptive Neuro-Fuzzy Inference System- A Survey", International Journal of Computer Applications, Vol.123, No.13, August 2015.

[12] Kompan Chomsamutr, Somkiat Jongprasithporn" Optimization Parameters of tool life Model Using the Taguchi Approach and Response Surface Methodology", IJCSI International Journal of Computer Science Issues, Vol. 9, Issue 1, No 3, 2012. 


\title{
تحقيق ألامثلية لعوامل التثغيل للخشونة السطية في السطوح المعقدة للمواد المركبة
}

\author{
ريم صباح خزعل**

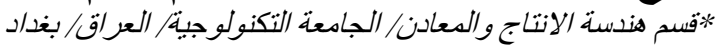

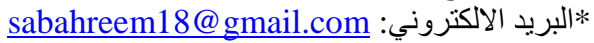 \\ wisamuot@yahoo.com البريد الالكتروني:
}

يهدف هذا البحث الى تحقيق الامثلية لعوامل التشغيل ( سرعة القطع ومعدل التغذية وعمق القطع وقطر الاداة و عدد الحدود القاطعة الموجودة في العدة)

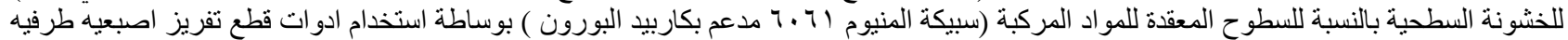

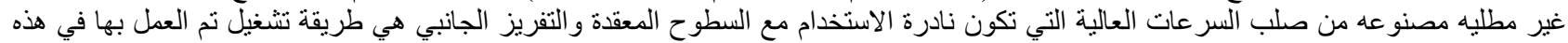

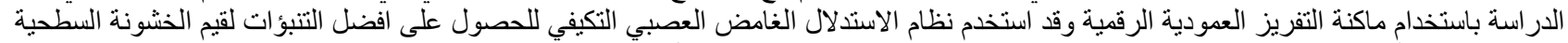

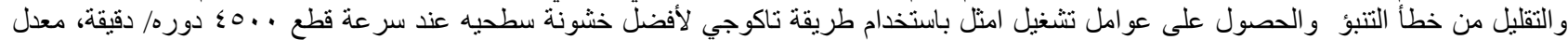

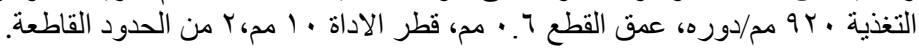

